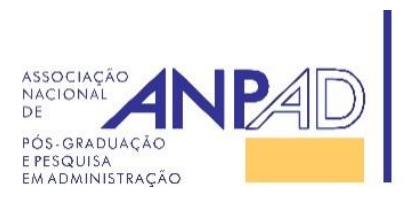
Disponível em
http://www.anpad.org.br/rac
RAC, Rio de Janeiro, v. 22, n. 1, art. 3,
pp. 46-69, janeiro/fevereiro, 2018
http://dx.doi.org/10.1590/1982-7849rac2018160213
$(c)$ EY

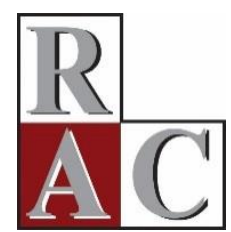

\title{
Redes de Franquias Estrangeiras e Domésticas em um Mercado Emergente: Análise Comparativa
}

\author{
Foreign and Domestic Franchise Chains in an Emerging Market: A Comparative \\ Analysis
}

Victor Ragazzi Isaac ${ }^{1}$ Pedro Lucas Resende Melo ${ }^{1}$

Felipe Mendes Borini ${ }^{2}$

Universidade Paulista ${ }^{1}$ Escola Superior de Propaganda e Marketing ${ }^{2}$

Artigo recebido em 03.08.2016. Última versão recebida em 11.08.2017. Aprovado em 12.09.2017. 


\title{
Resumo
}

$\mathrm{O}$ artigo tem como objetivo analisar as diferenças existentes no processo de constituição das redes de franquias estrangeiras que atuam no mercado brasileiro e as redes de franquias domésticas brasileiras. Este processo compreende a instalação, a manutenção e a expansão das redes. A revisão teórica e o desenvolvido teórico se baseiam na Teoria da Agência e na Teoria da Escassez de Recursos. Por meio de uma regressão logística com 147 redes de franquias brasileiras e 41 redes de franquias estrangeiras em operação no mercado brasileiro, observouse que as redes de franquias estrangeiras e domésticas se diferem nas três etapas do processo de constituição: instalação, manutenção e expansão. Complementarmente, foram realizadas três entrevistas semiestruturadas com três franqueadores de redes de franquias estrangeiras. Os resultados apontam que as franquias estrangeiras apresentam uma maior taxa de investimento e manutenção do que as redes de franquias brasileiras, no entanto exibem uma menor capacidade de monitoramento e controle do que as redes de franquias brasileiras. Por outro lado, ao contrário do esperado, observou-se que as redes de franquias estrangeiras atuantes no Brasil apresentam uma menor taxa de crescimento do que as redes de franquias domésticas deste país.

Palavras-chave: redes de franquias; internacionalização; teoria da escassez de recursos; teoria da agência; mercados emergentes.

\begin{abstract}
This article aims to analyze the differences between the process of establishing foreign franchises and those of domestic franchise chains operating in the Brazilian market. This process includes the installation, maintenance and expansion of chains. The theoretical review and theory developed are based on Agency Theory and Resource Scarcity Theory. A logistic regression with 147 chains of Brazilian franchises and 41 chains of foreign franchises operating in Brazil showed that foreign and domestic franchise chains differ in three stages of the establishment process: installation, maintenance and expansion. In addition, three semi-structured interviews were conducted with three franchisors from foreign chains. The results show that foreign franchises have a higher rate of investment and maintenance than Brazilian franchises, however, they exhibit a lower capacity for monitoring and control than Brazilian franchise chains. On the other hand, contrary to expectations, foreign franchise chains active in Brazil have a lower growth rate than domestic franchise chains.
\end{abstract}

Key words: franchise chains; internationalization; resource scarcity theory; agency theory; emerging markets. 


\section{Introdução}

O sistema de franquia tem obtido um rápido crescimento em países emergentes nos últimos anos (Hoffman, Munemo, \& Watson, 2016; Welsh \& Alon, 2002). Particularmente no mercado brasileiro, o crescimento no número de redes de franquias foi de aproximadamente $25 \%$ nos últimos cinco anos, passando de 2.426 para 3.039 redes de franquias (Associação Brasileira de Franchising [ABF], 2016a). Segundo Schreiber e Szysko (2014) e Plá (2001), este fenômeno é influenciado pelo elevado custo de financiamento encontrado no Brasil, aliado ao baixo risco que o sistema de franquia proporciona, por meio da marca já consolidada no mercado e do constante suporte fornecido pelo franqueador ao franqueado. Por outro lado, diversas marcas provenientes de países desenvolvidos têm se utilizado estrategicamente do sistema de franquias para se instalar em mercados emergentes, pois esses permitem que o franqueador consiga, por meio do franqueado local, obter maior acesso a recursos e ajustes às instituições locais (Hosksson, Eden, Lau, \& Wright, 2000).

Neste contexto, tem-se visualizado uma crescente busca na compreensão do modelo de franchising e da competitividade das redes de franquias em atuação nos mercados emergentes, em especial daquelas estrangeiras oriundas de países desenvolvidos (Baena, 2015; Dant \& Grünhagen, 2014; Paswan \& Rajamma, 2016; Welsh, Alon, \& Falbe, 2006). Os estudos, de um modo geral, analisam as redes de franquias estrangeiras em operação nos mercados emergentes, tal como o Brasil, investigando: (a) aspectos institucionais do país de origem ou de destino (Baena, 2015; Baena \& Cerviño, 2014; Jeon, Meiseberg, Dant, \& Grünhagen, 2016); (b) modos de entrada em mercados emergentes e desenvolvidos (Baena, 2009, 2015); (c) capacidade consumidora dos mercados emergentes (Alon, Welsh, \& Falbe, 2010; Baena, 2015; Welsh et al., 2006); e (d) vantagens competitivas obtidas pelas redes de franquias estrangeiras que atuam em mercados emergentes (Aliouche, Fernandez, Chanut, \& Gharbi, 2015; Dant \& Grünhagen, 2014; Dant, Grünhagen, \& Windsperger, 2011).

Além dessa variedade de estudos e temas, algumas pesquisas propõem a comparação dos elementos estruturantes das redes de franquias domésticas e estrangeiras e/ou internacionalizadas (Elango, 2007; Kalnins, 2005; Kedia, Ackerman, \& Justis, 1995; Lafontaine \& Kaufmann, 1994; MarizPérez \& García-Álvarez, 2009; Melo, Borini, Oliveira, \& Parente, 2015a; M. I. C. Pedro, 2009). Tais elementos estruturantes são representados por meio de proxies como: (a) a taxa de investimento (estágio de instalação) (Shane, 1996a, 1998); (b) a taxa de manutenção (estágio de manutenção) (Kacker, Dant, Emerson, \& Coughlan, 2016; Shane, 1996a, 1998); (c) a capacidade de monitoramento (estágio de manutenção) (Doherty, Chen, \& Alexander, 2014; Huszagh, Huszagh, \& McIntyre, 1992; Lafontaine \& Kaufmann, 1994); e (d) a capacidade de crescimento (estágio de expansão) (Elango, 2007; Kedia et al., 1995). São proxies que, em conjunto, representam o processo de constituição de uma rede de franquia (Greiner, 1972; Klann, Klann, Postai, \& Ribeiro, 2012; Miller \& Friesen, 1984), caracterizado pelas etapas de: (a) instalação das unidades, (b) manutenção das atividades existentes e a (c) expansão visando novas unidades.

Todavia, os estudos acima referidos não abordam, em conjunto, todas as etapas do processo de constituição de uma rede de franquia. O que temos são comparações isoladas de cada uma das etapas, ou de algumas etapas, mas não de todo o processo. Tecnicamente, isso pode levar à tomada de decisão incorreta, pois uma das etapas pode ser vantajosa para a franquia estrangeira, enquanto outra, não, e vice-versa. Em outras palavras, analisar cada etapa isoladamente incorre no risco da miopia na tomada de decisão, por não discernir todo o processo. Desse modo, levantamos a seguinte questão: existem diferenças nas etapas do processo de constituiç̧ão das redes de franquias estrangeiras e domésticas em operação em um mercado emergente, especificamente no Brasil? Temos como objetivo defender a tese de que existem diferenças nas etapas do processo de constituição quando comparamos franquias estrangeiras e domésticas. Especificamente, defendemos que nas duas primeiras etapas (instalação e manutenção), as operações para franquias estrangeiras em mercados emergentes são mais custosas, ou seja, requerem dos franqueadores e franqueados maior dispêndio. Contudo, apesar do maior custo inicial e intermediário, na última etapa, a de expansão, as franquias estrangeiras têm um crescimento relativo superior às domésticas, em virtude de seu prestígio e reputação em mercados emergentes. 
No nosso entender, essa contradição, de algumas etapas se mostrarem menos favoráveis e outras mais para as franquias estrangeiras, é a contribuição à literatura. Primeiro porque, ao compreender as três etapas do processo de constituição, mostramos a natureza dinâmica do franchising. Se a análise fosse isolada, atentando-se apenas para uma ou outra etapa do processo de constituição da franquia, poderíamos chegar a resultados não conclusivos. Logo, em relação aos estudos comparativos acerca dos elementos estruturantes (Elango, 2007; Kalnins, 2005; Mariz-Pérez \& García-Álvarez, 2009; Melo et. al., 2015a; M. I. C. Pedro, 2009; Lafontaine \& Kaufmann, 1994; Shane, 1998), nosso artigo mostra a necessidade de se analisar como um todo o processo de constituição de uma rede de franquia. Essa perspectiva não acresce somente ao conhecimento sobre as franquias, como também é importante para decisões gerenciais, pois evidencia que as franquias estrangeiras podem ter resultados de expansão melhores ao final, mesmo sendo mais penoso no início da implementação. Ressaltamos que essa contribuição está alinhada com as novas fronteiras de pesquisa em franquias em mercados emergentes (Baena \& Cerviño, 2014; Dant \& Grünhagen, 2014; Grünhagen \& Terry, 2017; Paswan \& Rajamma, 2016).

A seguir, apresentamos o referencial teórico que está estruturado sobre as âncoras da Teoria da Escassez de Recursos e da Teoria da Agência para explicar as etapas do processo de constituição das franquias e os argumentos de nossas hipóteses. Posteriormente, apresenta-se a metodologia do estudo realizado com dados quantitativos e qualitativos.

\section{Revisão Teórica}

A Teoria da Escassez de Recursos (Madanoglu \& Karadag, 2016; Oxenfeld \& Kelly, 1969) e a Teoria da Agência (Kacker et al., 2016; Lafontaine, 1992; Jensen \& Meckling, 1976) são dois enfoques teóricos centrais para o entendimento do processo de constituição do modelo de franchising, a saber, as etapas de instalação, manutenção e expansão.

A Teoria da Escassez de Recursos se funda na ausência de recursos por parte do empreendedor ao constituir uma rede de franquia, nesta figura do franqueador. Por não possuir recursos financeiros suficientes, este empreendedor recorre ao franqueamento das suas unidades. Da outra parte, os franqueados contribuem tanto com recursos financeiros como humanos em troca de recursos e competências gerenciais fornecidos pelo franqueador, como o know-how de operação do negócio, o suporte ao franqueado e a marca da franquia (Madanoglu \& Karadag, 2016; Oxenfeld \& Kelly, 1969; Sun \& Lee, 2016). Igualmente, a Teoria da Escassez de Recursos também tem sido utilizada para explicar o processo de internacionalização das redes de franquia. Isso se dá devido à rede de franquia precisar de recursos, no momento de sua internacionalização, que auxiliem na instalação das unidades, no seu acompanhamento e no plano de expansão internacional (Castrogiovanni, Combs, \& Justis, 2006; Combs, Ketchen, Shook, \& Short, 2011).

A escassez de recursos que influencia a adoção pelo empresário do modelo de franchising para novas unidades é recompensada pelo pagamento, por parte do franqueado, das taxas de investimento e manutenção. A primeira é relacionada à etapa da instalação no processo de constituição da franquia, e a segunda é referente à etapa de manutenção do processo. A Figura 1 ilustra as etapas e as taxas. 


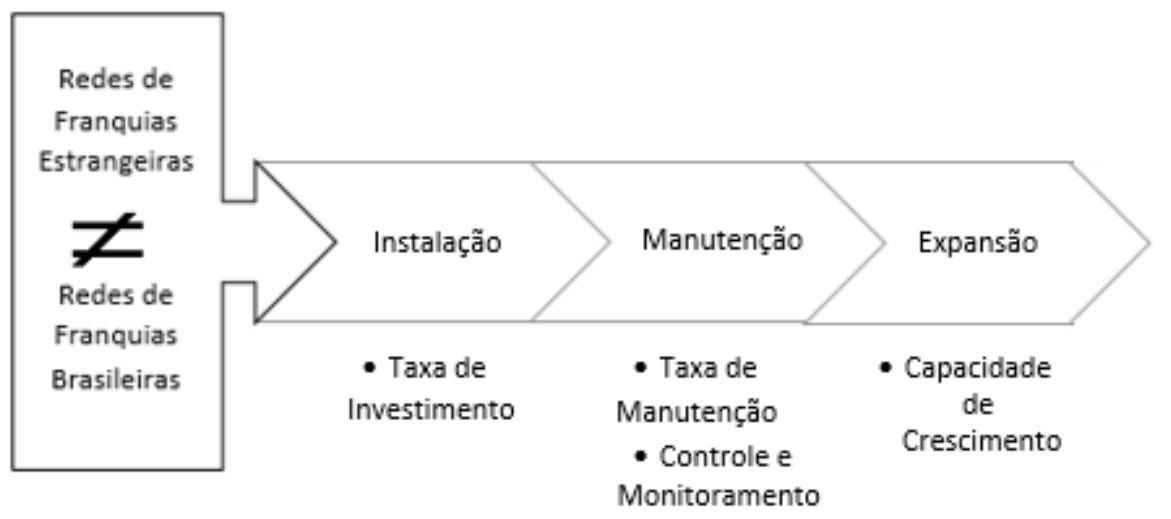

Figura 1. Etapas do Processo de Constituição de uma Franquia Fonte: Elaborado pelos autores.

Por sua vez, uma vez constituída a franquia, emergem os axiomas da Teoria da Agência, sendo que, em virtude das relações existentes entre as partes envolvidas, surgem franqueador (principal) e franqueado (agente), que podem possuir interesses divergentes na busca da maximização do lucro de cada parte (Brookes, Altinay, \& Aktas, 2015; Jensen \& Meckling, 1976). Segundo Wu (2015), o franqueador, para reduzir os custos de agência e o oportunismo, necessita estabelecer mecanismos de controle e monitoramento, além de criar todo um aparato para os franqueados em prol da expansão da rede. Nesse sentido, ainda que o franqueador (principal) seja o detentor de informações, expertise e know-how fundamentais para o desenvolvimento da rede de franquia, caberá ao franqueado, que não possui tais atributos, operacionalizar a unidade de franquia no seu dia a dia e sentir-se atraído para novos investimentos (Garg, Priem, \& Rasheed, 2013; Gonzalez-Diaz \& Solis-Rodriguez, 2012). A Figura 1 também apresenta o monitoramento e capacidade de crescimento relativos, respectivamente, à manutenção e à expansão.

\section{Hipóteses}

Nessa seção são apresentadas quatro hipóteses referentes a cada um dos elementos das três etapas do processo de constituição, tal como na Figura 1.

\section{Estágio de instalação - taxa investimento no país de destino}

A taxa de investimento é formada por três montantes, sendo que o primeiro elemento deriva da taxa de franquia que será cobrada pelo franqueador ao franqueado, servindo como uma taxa de adesão à rede de franquia. É considerada uma taxa inicial pela qual o franqueador se disponibilizará a fornecer a marca da rede de franquia ao franqueado (Gigliotti, 2012). Posteriormente, haverá a cobrança da taxa de instalação, relativa à aquisição de equipamentos, treinamento de pessoal e do franqueado, à compra de estoque, ao desenvolvimento do layout da unidade da rede de franquia e a quaisquer outros gastos com matérias físicas necessárias para se inicializar a operação da unidade da rede de franquia (Gigliotti, 2012; M. I. C. Pedro, 2009). Por fim, o franqueador deverá ter disponível um capital de giro, utilizado para prover suporte ao franqueado durante as operações da unidade da rede de franquia por ele adquirida (Gigliotti, 2012; Juste, Palacios, \& Redondo, 2005).

Deve-se ressaltar que a taxa de investimento tem função dupla, servindo tanto para atrair investidores interessados em assumir um maior retorno proporcional ao montante investido, como possibilitar um maior acesso ao investimento requerido pelo franqueador. Salienta-se, ainda, que em sua composição existe o peso do status e do prestígio da marca da rede de franquia, uma vez que se relacionam proporcionalmente ao valor cobrado. Sendo assim, quanto menores esses fatores, a tendência é a adoção de uma baixa taxa de investimento, inclusive com o intuito de atrair o maior número possível de franqueados (Shane, Shankar, \& Aravindakshan, 2006). 
Outro fator que pode contribuir para a variação da taxa de investimento decorre do número de unidades em operação no país de destino. Redes com poucas unidades tendem a incorrer em maiores custos operacionais, por não serem capazes de compartilhar os seus custos fixos com um maior número de franqueados. Esse fator encarece tanto o custo de investimento como o de manutenção de uma franquia (Polo-Redondo, Bordonaba-Juste, \& Palacios, 2011).

Nessa esteira, as redes de franquias estrangeiras atuantes em mercados emergentes tendem a cobrar uma taxa de investimento superior, pois em geral têm um elevado status e prestígio de marca, por apresentarem uma marca internacional. Ademais, procuram selecionar de maneira mais criteriosa os candidatos a franqueados, além de possuírem um menor número de unidades no país em relação às domésticas (M. I. C. Pedro, 2009; Polo-Redondo et al., 2011; Shane et al., 2006; Welsh \& Alon, 2002). Mediante o exposto, é proposto que:

H1: As redes de franquias estrangeiras requerem uma maior taxa de investimento no país de destino do que as redes domésticas.

\section{Estágio de manutenção - taxa de manutenção no país de destino}

A taxa de manutenção, conhecida como taxa de royalties, é uma taxa mensal cobrada pelo franqueador ao franqueado, a fim de realizar a manutenção da rede de franquia. Será utilizada para prestação de serviços e benefícios contínuos oferecidos por parte do franqueador, para o desenvolvimento de produtos e serviços prestados pela rede de franquia (Alon \& Mckee, 1999; Kacker et al., 2016).

Noutro enfoque, a taxa de royalties também serve como um meio de atrair investidores (franqueados) e obter a comercialização da marca (Choo, Mazzarol, \& Soutar, 2007). Sendo assim, quanto menor for o valor cobrado na taxa de manutenção, mais a franquia tem que cogitar num negócio em escala. Ademais, o valor cobrado na taxa de royalties também está vinculado ao status da rede de franquia e ao prestígio da marca, uma vez que quanto maior o status e prestígio da rede de franquia, maior será o valor cobrado na taxa de manutenção (Choo et al., 2007; Polo-Redondo et al., 2011; Shane et al., 2006).

Nesse sentido, as taxas de royalties cobradas pelas redes de franquias estrangeiras tendem a ser maiores do que aquelas cobradas pelas redes de franquias domésticas de mercados emergentes. Isso ocorre porque as redes de franquias estrangeiras dispõem de um maior status e prestígio global, possuindo, também, um gasto mais elevado para manter as operações no mercado exterior (Dant, \& Grünhagen, 2014; Jayachandran, Kaufman, Kumar, \& Hewett, 2013). Em contraponto, as taxas das franquias domésticas são inferiores, pois precisam priorizar a sua expansão no mercado interno, visando atrair franqueados, como uma alternativa para obter um maior status e prestígio da marca (Elango, 2007; Mariz-Pérez \& García-Álvarez, 2009). A partir disso, pode-se afirmar que:

H2: As redes de franquias estrangeiras requerem uma maior taxa de manutenção no país de destino do que as redes domésticas.

\section{Estágio de manutenção - capacidade de monitoramento e controle no país de destino}

Segundo Shane (1996b), a capacidade de monitoramento e controle de uma franquia se desenvolve a partir do momento em que ela possui um maior tempo de atuação no mercado e uma maior dispersão geográfica no ambiente doméstico em que atua. Tal condição faz com que o franqueador desenvolva métodos e mecanismos de controle e monitoramento junto à rede de franquia e ao franqueado. Dentre esses métodos de monitoramento e controle há: (a) o contrato assinado por ambas as partes, que prevê penalidades ao franqueado caso não aja de acordo com o acordo afirmado, (b) as taxas cobradas pelo franqueador sobre o franqueado e (c) o período de duração do contrato assinado entre o franqueador e franqueado, uma vez que quanto maior for o período da avença maior será o 
controle do franqueador sobre o franqueado (Doherty et al., 2014; Mariz-Pérez \& Garcia-Álvarez, 2009).

É comum que o franqueador encontre dificuldades, ao se internacionalizar, para manter o monitoramento e o controle das operações da rede de franquia, em razão da extensão e dispersão geográfica das suas unidades (Quinn, 1998). Acrescem a esses fatores as distâncias culturais, psíquicas e institucionais (Eroglu, 1992; Gillis, Combs, \& Ketchen, 2014; Quinn, 1998), que tendem a aumentar quando as operações de países desenvolvidos se direcionam para mercados emergentes (Meyer, Estrin, Bhaumik, \& Peng, 2009).

Essas diferenças potencializam as dificuldades das franquias estrangeiras que buscam atuar em mercados emergentes, no que tange à manutenção de sua capacidade de monitoramento e controle. Além dessas dificuldades já apontadas, a manutenção também é intrincada por problemas relativos: (a) à assimetria de informação, decorrente da distância entre a sede da rede de franquia e a unidade internacionalizada; (b) ao fornecimento e utilização dos materiais para prestação de serviços; e (c) ao relacionamento entre o franqueador e o franqueado (Khan, 2016; Lafontaine, 1992; Mariz-Pérez \& García-Álvarez, 2009; Shane, 1996b). Diante da discussão apresentada, deduz-se que:

H3: As redes de franquias estrangeiras possuem uma menor capacidade de monitoramento e controle no país de destino do que as redes domésticas.

\section{Estágio de expansão - capacidade de crescimento no país de destino}

$\mathrm{Na}$ última década, os mercados emergentes obtiveram destaque como destino de internacionalização das redes de franquia, podendo ser observado tal acontecimento mediante a análise do crescimento na quantidade de redes de franquias estrangeiras atuantes no Brasil, China, Rússia e outros países emergentes (Alon \& Banai, 2000; Alon \& Welsh, 2002; Hoffman et al., 2016). Esse desenvolvimento do mercado atraiu a migração das redes de franquias provenientes de países desenvolvidos devido à alta aceitação das marcas estrangeiras pelos consumidores emergentes, bem como em razão de fatores econômicos, como a crise mundial (Dant \& Grünhagen, 2014).

A expressão internacional das marcas globais, o prestígio que estas possuem nos mercados emergentes de destino e os elevados faturamentos por elas obtidos nas diversas unidades existentes pelo mundo são características que cooperam a seu favor na obtenção de crescimento nesses nichos e na atração de interesse tanto de franqueados como consumidores (Elango, 2007; Lourenço \& Brandão, 2013; Shane, 1996b). Portanto, a atuação em mercados emergentes, por parte das redes de franquias, ocorre devido ao fato de estes mercados apresentarem um gradativo crescimento do mercado consumidor, ansioso por marcas globais (Alon, Toncar, \& Le, 2002; Hoffman et al., 2016). Mediante o exposto, deduz-se que:

H4: As redes de franquias estrangeiras possuem uma maior capacidade de crescimento em países emergentes do que as redes domésticas.

\section{Metodologia}

Nesta pesquisa foi adotada a estratégia de triangulação metodológica de caráter sequencial, sendo que os resultados da análise dos dados quantitativos serviram de alicerce para a estruturação do uso da abordagem qualitativa (Morse, 1991). Portanto, em um primeiro momento, foi adotada a abordagem quantitativa, para comparação entre as redes de franquias brasileiras e as redes de franquias estrangeiras atuantes no Brasil. Em um segundo turno, utilizou-se a abordagem qualitativa perante as redes de franquias estrangeiras atuantes no Brasil, com a finalidade de que os resultados obtidos na hipótese 4, por meio dos dados quantitativos, pudessem ser confrontados, de maneira a se chegar a uma maior compreensão sobre o como e o porquê da ocorrência dos resultados. 


\section{Abordagem quantitativa}

Segundo a ABF (2014), em 2013 foram contabilizadas 2.703 redes de franquias atuantes no mercado brasileiro. Deste total, 2.497 redes de franquias são brasileiras e 206 redes de franquias são estrangeiras. Mediante tais dados, utilizou-se critérios de escolha para homogeneizar as amostras entre as redes de franquias brasileiras e as redes de franquias estrangeiras que atuam no mercado brasileiro. Estes critérios são constituídos por indicadores presentes nos anuários da ABF (Guia Oficial de Franquias) e da Revista Pequenas Empresas \& Grandes Negócios (Guia de Franquias); este último, auditado pelo Serasa Experian. Tem-se como referência e validação, na utilização destes critérios, a pesquisa realizada por Melo, Borini, Oliveira e Parente (2015a), por terem realizado a seleção de redes brasileiras domésticas em uma comparação com as redes brasileiras internacionalizadas.

Assim, os indicadores utilizados para realizar a seleção da amostra são os seguintes: (a) Cotação, (b) Selo de excelência, (c) Média Final. Esta composição deu origem a um ranking de franquias resultante dos indicadores acima. Foram excluídas, da seleção inicial das redes de franquias brasileiras, as que apresentavam informações parciais no Guia de Franquias (PEGN), bem como as redes classificadas como outliers. Após realizarmos o cruzamento dos índices anteriores, foram selecionadas 147 redes de franquias brasileiras com maior score no ranking.

A Tabela 1 descreve estes critérios:

Tabela 1

Critérios para seleção de Amostra das Franquias Brasileiras

\begin{tabular}{|c|c|c|c|}
\hline Critério & Composição índice & Descrição & $\begin{array}{l}\text { Critério: Índice de seleção } \\
\text { autor }\end{array}$ \\
\hline Cotação & $\begin{array}{l}\text { Revela a classificação } \\
\text { geral da rede. }\end{array}$ & $\begin{array}{l}5 \text { estrelas - Excelente } \\
4 \text { estrelas - Ótimo } \\
\mathbf{3} \text { estrelas - Bom } \\
2 \text { estrelas - Regular }\end{array}$ & $\begin{array}{l}5 \text { estrelas }-5 \text { pontos } \\
4 \text { estrelas }-4 \text { pontos } \\
3 \text { estrelas }-3 \text { pontos } \\
2 \text { estrelas }-2 \text { pontos }\end{array}$ \\
\hline $\begin{array}{l}\text { Selo de excelência } \\
\text { ABF }\end{array}$ & $\begin{array}{l}\text { Selo de excelência } \\
\text { outorgado pela associação } \\
\text { representativa do setor. }\end{array}$ & Sim ou Não & $\begin{array}{l}\text { Sim }-1 \text { ponto } \\
\text { Não }-0 \text { ponto }\end{array}$ \\
\hline Média & $\begin{array}{l}\text { Resultado da ponderação } \\
\text { dos índices de } \\
\text { desempenho (peso } 0,30) \text {, } \\
\text { qualidade }(0,30) \text { e } \\
\text { satisfação }(0,40) \text {. }\end{array}$ & $\begin{array}{l}\text { Desempenho da rede - Tem } \\
\text { como base os índices de } \\
\text { crescimento do faturamento e } \\
\text { do }{ }^{\circ} \text { de lojas. } \\
\text { Qualidade da rede - Tem } \\
\text { como base três indicadores: } \\
\text { suporte ao franqueado, força da } \\
\text { marca, solidez e transparência. } \\
\text { Satisfação do franqueado - } \\
\text { Tem como base: a qualidade } \\
\text { do treinamento, da consultoria, } \\
\text { do manual de operações e do } \\
\text { nível de comunicação com os } \\
\text { franqueados. }\end{array}$ & $\begin{array}{l}\text { Nota estabelecida pelo guia } \\
\text { - } 0 \text { a } 10 \text { pontos. }\end{array}$ \\
\hline Segmento & Setor de atuação & Categoria conforme $\mathrm{ABF}$ & $\begin{array}{l}\text { Proporcional à amostra das } \\
\text { franquias estrangeiras por } \\
\text { setor. }\end{array}$ \\
\hline
\end{tabular}

Nota. Fonte: Melo, P., Borini, F. M., Oliveira, M., Jr., \& Parente, R. C. (2015a). Internationalization of Brazilian franchise chains: A comparative study (p. 263). Revista de Administração de Empresas, 55(3), 258-272. http://dx.doi.org/10.1590/S0034759020150303 
A segunda parte da composição da amostra é formada pelas redes de franquias estrangeiras que atuam no Brasil. No total, foram constatadas 46 redes de franquias estrangeiras nos anuários de 2013. Entretanto, após o tratamento estatístico visando extrair outliers, chegou- se ao total de 41 redes de franquiais estrangeiras. Desse cenário resulta a variável dependente do estudo: a origem da rede de franquia selecionada, constituída de uma variável binominal, sendo: (0) para rede brasileira e (1) para rede de franquia estrangeira. $\mathrm{O}$ ano de 2013 foi o escolhido, pois, em comparação aos anuários disponíveis, era o que tinha o maior número de franquias estrangeiras.

As variáveis independentes estão descritas a seguir e são formadoras dos constructos: taxa de investimentos, royalties, monitoramento e crescimento. A taxa de investimento (H1) foi formada pelas seguintes variáveis independentes: (a) taxa de franquia para a concessão de uma unidade e (b) capital inicial, constituído pelo capital necessário para instalação da unidade (alpha $=0.801)$ (Alon, 2001; Elango, 2007; Lafontaine, 1992; Shane, 1996b, 1998). Para a composição da taxa de manutenção (H2), utilizou-se a seguinte variável independente: Este constructo foi formado somente pela variável taxa de royalties (\%). Neste caso não é necessário realizar o alpha (só se utiliza quando há 2 ou mais variáveis formando o constructo) (Alon, 2001; Diaz-Bernardo, 2012; Elango, 2007; Lafontaine, 1992; Melo et al., 2015a; Shane, 1996a, 1996b). A capacidade de monitoramento e controle (H3) foi composta de duas variáveis independentes, sendo elas: (a) o número de estados em operação e (b) o número de anos em operação por franchising (alpha $=0.516$ ) (Doherty et al., 2014; Elango, 2007; Mariz-Pérez \& GarcíaÁlvarez, 2009; Melo et al., 2015a; Shane, 1996a, 1996b). Por fim, a capacidade de crescimento (H4) foi levada em consideração para a formulação das seguintes variáveis independentes: (a) variação do número total de unidades da rede anualmente (\%) e (b) aumento relativo do faturamento anual da rede em (\%) $($ alpha = 0.506) (Castrogiovanni et al., 2006; Diaz-Bernardo, 2012; Huszagh et al., 1992; MarizPérez \& García-Álvarez, 2009; Shane 1996b, 1998).

Um perfil da amostra é apresentado na Tabela 2. É interessante notar que, em termos de crescimento, em média, o aumento do faturamento foi consideravelmente maior nas franquias nacionais. Por sua vez, em termos de aumento de unidades, as franquias se equivalem ao se analisar o desvio padrão. O capital inicial denota o custo maior das estrangeiras, o que se reflete, também, na taxa de franquia e na taxa de royalties. De maneira geral, a média das estrangeiras é quase o dobro das nacionais. Por sua vez, a variância não é grande quanto ao número de estados e idade. Em média, as franquias estão na metade dos estados brasileiros e têm entre 10 a 12 anos de operações.

Tabela 2

Análise Descritiva

\begin{tabular}{|c|c|c|c|c|c|c|c|c|}
\hline & & $\begin{array}{c}\text { Aumento do } \\
\text { faturamento } \\
\text { anual (em \%) }\end{array}$ & $\begin{array}{c}\text { Aumento } \\
\text { do n }{ }^{\circ} \text { de } \\
\text { unidades } \\
(\text { em \%) }\end{array}$ & $\begin{array}{c}\text { Capital } \\
\text { inicial }(e m \\
\text { mil } \mathbf{R} \$)\end{array}$ & $\begin{array}{c}\text { Taxa de } \\
\text { franquia } \\
\text { (em mil } \mathbf{R} \$)\end{array}$ & $\begin{array}{c}\text { Taxa de } \\
\text { royalties } \\
\text { (\% do fat.) }\end{array}$ & Estados & $\begin{array}{c}\text { Anos de } \\
\text { operação da } \\
\text { franquia }\end{array}$ \\
\hline \multirow[t]{2}{*}{ Nacional $n=147$} & Média & 37,26 & 19,74 & 204,21 & 36,94 & 2,76 & 13 & 12,07 \\
\hline & DesvPad & 61,68 & 23,02 & 176,85 & 23,58 & 3,42 & 9 & 8,85 \\
\hline \multirow[t]{2}{*}{ Estrangeira $n=41$} & Média & 5,79 & 15,7 & 405,20 & 70,30 & 4,93 & 12 & 9,61 \\
\hline & DesvPad & 16,57 & 36,89 & $1.323,13$ & 89,66 & 6,86 & 10 & 7,64 \\
\hline
\end{tabular}

Nota. Fonte: Elaborada pelos autores.

\section{Abordagem qualitativa}

Em complemento, foram realizadas entrevistas semiestruturadas (Godoi \& Mattos, 2006), em especial para entender as entrelinhas de um dos resultados que veio a se confirmar inversamente ao esperado. Essas entrevistas envolveram três representantes dos franqueadores de redes de franquias estrangeiras que atuam no Brasil. As informações foram fornecidas pelos Diretores Gerais no Brasil, no caso A e B, e pelo Diretor de Expansão, no Caso C. Esses executivos foram contatados, por 
conveniência, a partir de uma listagem encaminhada pela ABF. Foram enviados e-mails para vinte e dois franqueadores de redes de franquias estrangeiras que atuam no Brasil. Desse total, três franqueadores se disponibilizaram para contribuir com o estudo proposto. Com esses três foram realizadas entrevistas presencialmente, que ocorreram no estabelecimento comercial dos franqueadores no mês de junho de 2017. Os franqueadores selecionados fazem parte dos segmentos de Intermediação de Negócios (Rede A), Limpeza e Conservação (Rede B) e Educação e Treinamento (Rede C).

A rede de franquia estrangeira A tem origem norte-americana e atua no segmento de intermediação de negócios, operando tanto na venda quanto na compra de micro, pequenas e médias empresas de negócios. A empresa foi fundada em 1978, tendo adotado o sistema de franchising em meados de 1993 e iniciado o processo de internacionalização em 1994. As suas operações no mercado brasileiro começaram em 2010.

A rede de franquia estrangeira $\mathrm{B}$ é de origem norte-americana e atua no segmento de limpeza e conservação. Os serviços oferecidos por essa rede de franquia estão relacionados à limpeza, conservação e manutenção de imóveis, possuindo como foco estabelecimentos comerciais que tenham grande circulação de pessoas, como centros religiosos, universidades e academias de ginástica. Essa empresa foi fundada em 1991 e no ano seguinte adotou o sistema de franchising. Em 1995, a rede de franquia começou a se internacionalizar. Já no Brasil, a empresa iniciou suas operações em 2010.

A rede de franquia estrangeira $C$ é originária do Japão e atua no segmento de educação e treinamento. No Brasil, a rede de franquia se utiliza de uma metodologia própria de ensino para crianças, com o objetivo de ensinar disciplinas como matemática, português, japonês e inglês. A empresa foi fundada em 1958, tendo adotado, no mesmo ano, o sistema de franchising. A instalação da primeira unidade no Brasil ocorreu em 1977.

O roteiro da entrevista foi constituído por quatro partes semiestruturadas referentes aos seguintes aspectos: (a) as dificuldades das redes de franquias estrangeiras para expansão no mercado brasileiro (Fladmoe-Lindquist \& Jacque 1995; Hoskisson, Eden, Lau, \& Wright, 2000); (b) diferenças entre os critérios de seleção de franqueados por parte dos franqueadores das redes de franquias estrangeiras e brasileiras (Brookes \& Altinay, 2011; Hitt, Dacin, Levitas, Arregle, \& Borza, 2000); (c) dificuldades de adaptação dos elementos do mix de marketing para o mercado brasileiro (Carvalho, 2000; Preble, 1993); e (d) a preservação e constituição dos atributos da marca internacionalmente (Douglas, Craig, \& Nijssen, 2001).

\section{Resultados}

Os testes estatísticos foram realizados observando-se as variáveis independentes que compõem as quatro hipóteses, e a variável dependente binária, que consiste na origem das redes de franquias que compõem este estudo. Portanto, em um primeiro momento, foi realizado o teste de correlação de Pearson, apreciado na Tabela 3. Verifica-se uma baixa correlação entre as variáveis independentes (valores abaixo de 0,500$)$, sendo apenas uma correlação significante, mas muito fraca $(0,204)$. Salientase que isto evita, a priori, a possibilidade de multicolinearidade. Ademais, foi apurado o Variance Inflation Factor (VIF) das variáveis na regressão (Tabela 4), todos com valor inferior a 5, o que elimina a chance de multicolinearidade. 
Tabela 3

\section{Teste de Correlação}

\begin{tabular}{lcccc}
\hline Variáveis & $\mathbf{1}$ & $\mathbf{2}$ & $\mathbf{3}$ & $\mathbf{4}$ \\
\hline 1 - Taxa de investimento & 1 & & & \\
2 - Taxa de manutenção & 0,020 & 1 & & \\
3 - Capacidade de monitoramento e controle & 0,090 & 0,110 & 1 & \\
4 - Capacidade de crescimento & $-0,120$ & $-0,080$ & $-0,204^{* *}$ & 1 \\
\hline
\end{tabular}

Nota. Fonte: Elaborada pelos autores. Observa-se que $* * \mathrm{p}<0,01 ; * \mathrm{p}<0,05$.

Tabela 4

\section{Modelo de Regressão Logística}

\begin{tabular}{llllllll}
\hline Hipóteses & Modelo1 & Modelo2 & Modelo3 & Modelo4 & Modelo5 & Exp(b) & VIF \\
\hline Constante & $-1,296$ & $-1,281$ & $-1,299$ & $-1,484$ & $-1,566$ & 0,209 & \\
\hline Taxa de investimento (H1) & $1,220^{* *}$ & & & & $1,329^{* *}$ & 3,779 & 1,019 \\
\hline Taxa de manutenção (H2) & & $0,505^{*}$ & & & $0,657^{* *}$ & 1,930 & 1,017 \\
\hline $\begin{array}{l}\text { Capacidade de monitoramento e controle } \\
\text { (H3) }\end{array}$ & & & $-0,255$ & & $-0,648^{* *}$ & 0,523 & 1,059 \\
\hline Capacidade de crescimento (H4) & & & & $-0,893^{*}$ & $-0,924^{* *}$ & 0,397 & 1,059 \\
\hline $\mathrm{R}^{2}$ de Nagelkerke & 0,096 & 0,044 & 0,012 & 0,063 & 0,226 & & \\
\hline Teste de Hosmer e Lemeshow & 6,198 & 5,105 & 3,130 & 53,299 & 7,598 & & \\
\hline & 0,625 & 0,277 & 0,926 & 0,000 & 0,474 & & \\
\hline
\end{tabular}

Nota. Fonte: Elaborada pelos autores.

Observa-se que $* * \mathrm{p}<0,01 ; * \mathrm{p}<0,05$.

Em seguida, foi aplicada a regressão logística (Tabela 4) para o teste de hipóteses. A opção pela regressão logística ocorre devido à variável dependente ser categórica binária, ou seja, o capital de origem da franquia é internacional ou nacional, além do fato de não se verificar a normalidade das variáveis independentes e a igualdade de matrizes de covariância (Hair, Celsi, Money, Samouel, \& Page, 2015). A aderência do modelo de regressão logística pode ser observada pelo respeito às condições de multicolinearidade (VIF menor que 5; ver Tabela 4) e heterocedasticidade (teste de White (chi = 19,78; p > 0,05 (0,1371)), o que indica que os resíduos são homocedásticos), além da medida de ajuste geral de Hosmer e Lemeshow com Qui-Quadrado 7,598 ( $>$ > 0,05) (ver modelo 5 na Tabela 4). Ademais, a análise de classificação do modelo mostra uma alta taxa de classificação correta $(80,32 \%)$ das observações analisadas. A análise de especificidade é ótima, uma vez que 97,96\% do modelo consegue classificar corretamente 144 dos casos das empresas de origem nacional. Por fim, a curva ROC mostra que a capacidade de o modelo discriminar a variável dependente é de 0,75 , o que é considerado aceitável e perto do ótimo (acima de 0,80) (Hair et al., 2015).

Foram realizados testes adicionais (ver Apêndice A) para verificar o impacto do setor da nossa amostra (moda, educação, alimentos, serviços de saúde e outros) na variável dependente, assim como para moderar, em especial, a taxa de investimento, porém os resultados não foram significantes, ou seja, não alteram o apresentado abaixo na Tabela 4.

A partir destes resultados, pode-se observar uma aderência ao modelo de $22,6 \%$ ( $\mathrm{R}^{2}$ de Nagelkerke) (Tabela 4, modelo 5). O valor de $\operatorname{Exp(b)~mostra~que,~das~variáveis~analisadas,~a~ordem~de~}$ 
importância delas é a taxa de investimento, seguida de taxa de manutenção, monitoramento e controle e crescimento.

Referente ao estágio de instalação da franquia, a partir dos resultados do modelo 1 e modelo 5, verifica-se a sustentação empírica para a hipótese 1 (H1), formada pelo constructo taxa de franquia e capital inicial. As redes de franquias estrangeiras que atuam no Brasil possuem maior taxa de investimento do que as redes de franquias brasileiras que atuam no mercado brasileiro. Ademais, o valor $\operatorname{Exp}(b)$ mostra que esse é o principal fator que distingue as franquias domésticas das estrangeiras.

Quanto ao estágio de manutenção (hipótese 2 (H2), formada pela taxa de manutenção), observouse que o modelo 2 e o modelo 5 atestam que as redes de franquias estrangeiras atuantes no mercado brasileiro possuem uma maior taxa de manutenção do que as redes de franquias estrangeiras que atuam no Brasil, sendo a taxa de manutenção o segundo aspecto que mais distingue os dois grupos. Já quanto à hipótese 3 (H3), observou-se que houve sustentação empírica no modelo 5 (o valor negativo, nesse caso, mostra que as franquias domésticas têm uma atuação em maior número de estados e uma experiência maior na operação por franchising), o que permite afirmar que as redes de franquias estrangeiras possuem uma menor capacidade de monitoramento e controle no mercado brasileiro do que as redes de franquias brasileiras atuantes no Brasil.

Por fim, quanto ao estágio de expansão, o que se observa é o inverso da hipótese 4 (H4) proposta, ou seja, as redes de franquias domésticas possuem maior capacidade de crescimento no mercado brasileiro do que as redes de franquias estrangeiras. Apesar de possuir o menor poder de distinção entre os grupos $(\operatorname{Ex}(b))$, esse resultado é interessante, pois mostra que além de os estágios instalação e manutenção da franquia estrangeira serem mais custosos, não há reflexo no que tange à recompensa de uma expansão relativamente maior. Os resultados obtidos na entrevista semiestruturada e sintetizados na Tabela 5 nos ajudam a entender essa constatação inversa ao esperado.

Tabela 5

Obstáculos para Expansão das Redes Estrangeiras

\begin{tabular}{|c|c|c|c|}
\hline Variáveis analisadas & Franqueador $\mathbf{A}$ & Franqueador B & Franqueador $\mathrm{C}$ \\
\hline Segmento de atuação & $\begin{array}{l}\text { Intermediação de } \\
\text { Negócios }\end{array}$ & Limpeza e Conservação & $\begin{array}{l}\text { Educação e } \\
\text { Treinamento }\end{array}$ \\
\hline $\begin{array}{l}\text { Tempo de atuação no Brasil } \\
\text { (em anos) }\end{array}$ & 7 & 7 & 40 \\
\hline $\begin{array}{l}\text { Dificuldades na expansão da } \\
\text { rede }\end{array}$ & $\begin{array}{c}\text { Diferenças culturais e } \\
\text { Desconhecimento da } \\
\text { marca }\end{array}$ & $\begin{array}{l}\text { Desconhecimento da } \\
\text { marca }\end{array}$ & Diferenças culturais \\
\hline $\begin{array}{l}\text { Critérios de seleção do } \\
\text { franqueado na matriz e o Brasil }\end{array}$ & Não há diferenças & Não há diferenças & Não há diferenças \\
\hline $\begin{array}{l}\text { Adaptação do mix de } \\
\text { marketing }\end{array}$ & $\begin{array}{l}\text { Apresentou dificuldades } \\
\text { na adaptação dos } \\
\text { produtos }\end{array}$ & $\begin{array}{l}\text { Não apresentou } \\
\text { dificuldade }\end{array}$ & $\begin{array}{l}\text { Apresentou dificuldade } \\
\text { na adaptação junto a } \\
\text { fornecedores, } \\
\text { distribuidores e na } \\
\text { elaboração das } \\
\text { promoções }\end{array}$ \\
\hline $\begin{array}{l}\text { Gestão da marca como } \\
\text { limitador para o crescimento }\end{array}$ & É um limitador & É um limitador & Não é limitador \\
\hline
\end{tabular}

Nota. Fonte: Elaborada pelos autores.

As dificuldades que explicam o menor crescimento das redes estrangeiras no mercado brasileiro, comparativamente com as franquias nacionais, são originárias dos seguintes fatores: diferenças culturais, desconhecimento da marca e adaptação do mix de marketing. Para o franqueador A e C, os 
fatores que geraram dificuldades para a expansão da rede foram relativos à questão cultural, em específico, às diferenças de idioma e de costumes do consumidor. Quanto ao desconhecimento da marca, apontado por A e B, refere-se ao fato de que, exceto algumas franquias com marcas globais, a maioria não tem uma marca conhecida pela maior parte da população. Logo, conquistar o reconhecimento, a reputação e a escolha dos consumidores exige considerável investimento e tempo. Por fim, as dificuldades na adaptação do mix de marketing, relatadas pelos franqueadores $\mathrm{A}$ e $\mathrm{C}$, se estendem por questões de adaptação do produto, promoção (promoção de vendas) e distribuição (cadeia de fornecimento e revenda).

Em suma, as hipóteses confirmadas são H1, H2 e H3. Entretanto, H4 é suportada de maneira inversa. A Tabela 6 sintetiza os resultados obtidos.

Tabela 6

\section{Síntese dos Resultados}

\begin{tabular}{lcc}
\hline Hipóteses & Resultado & $\begin{array}{c}\text { Grau de } \\
\text { Significância }\end{array}$ \\
\hline $\begin{array}{l}\text { H1: As redes de franquias estrangeiras requerem uma maior taxa de } \\
\text { investimento no país de destino do que as redes domésticas. }\end{array}$ & Suportada & $p<0,05$ \\
\hline $\begin{array}{l}\text { H2: As redes de franquias estrangeiras requerem uma maior taxa de } \\
\text { manutenção no país de destino do que as redes domésticas. }\end{array}$ & Suportada & $p<0,01$ \\
\hline $\begin{array}{l}\text { H3: As redes de franquias estrangeiras possuem uma menor capacidade de } \\
\text { monitoramento e controle no país de destino do que as redes domésticas. }\end{array}$ & Suportada & $p<0,05$ \\
\hline $\begin{array}{l}\text { H4: As redes de franquias estrangeiras possuem uma maior capacidade de } \\
\text { crescimento no país de destino do que as redes domésticas. }\end{array}$ & $\begin{array}{c}\text { Suportada de } \\
\text { maneira inversa }\end{array}$ & $p<0,05$ \\
\hline
\end{tabular}

Nota. Fonte: Elaborada pelos autores.

\section{Discussão dos Resultados}

As hipóteses 1 e 2 estão ancoradas na Teoria da Escassez de Recursos e são referentes à etapa de instalação e parte da manutenção, que tratam das taxas cobradas pelos franqueadores aos franqueados; e foram sustentadas estatisticamente. As redes de franquias estrangeiras que operam no mercado brasileiro, em sua maioria, possuem taxas de investimento e de manutenção maiores do que as redes de franquias brasileiras que operam no Brasil. Esse resultado reforça a concepção segundo a qual as redes de franquias estrangeiras em mercados emergentes impõem taxas superiores às domésticas, em muito resguardadas pelo prestígio e reputação da marca internacional, maior seleção dos franqueados e maior escopo de mercado. Isso quer dizer que as franquias que atuam no mercado doméstico precisam atrair um maior número de franqueados para sustentar as suas redes de franquias, e com isso diluir os custos das operações para se manterem competitivas tanto para a instalação de novas unidades como na manutenção das unidades existentes (Elango, 2007; Mariz-Pérez \& García-Álvarez, 2009; PoloRedondo et al., 2011). Esse resultado, a priori, é compatível com os resultados encontrados em estudos que salientam a taxa de investimento e o fato de as redes estrangeiras possuírem um gasto adicional para manter o monitoramento das unidades da rede de franquia, forçando com que a taxa de manutenção (royalties) seja, em sua maioria, mais elevada do que as taxas cobradas pelas redes de franquias domésticas (Polo-Redondo et al., 2011; Shane et al., 2006).

Por sua vez, a hipótese 3 possui como base de sustentação a Teoria da Agência e confirma um menor monitoramento e controle das redes de franquias estrangeiras que atuam no Brasil se comparadas com as redes de franquias brasileiras, corroborando os estudos de diversos autores (Doherty \& Quinn, 1999; Elango, 2007; Lafontaine, 1992; Mariz-Pérez, \& García-Álvarez, 2009; Shane, 1996b). Tal 
resultado se relaciona com a manutenção das unidades franqueadas, apresentando-se como um sinal de alerta, pois redes de franquias estrangeiras podem incorrer em problemas de agência. Isto é, elas estão mais suscetíveis ao maior risco de conflitos de interesse, oportunismo entre as partes envolvidas e quebra de padrões estabelecidos pelo franqueador (I. Pedro, Filipe, \& Reis, 2008; Merriles, 2014; Ni \& Alon 2010; Polo-Redondo et al., 2011). Tais problemas podem não só inviabilizar a expansão da rede, como interferir nas taxas de instalação e manutenção, se por ventura afetarem o prestígio e reputação da marca.

O resultado inverso ao que propomos na tese de nosso artigo corresponde à hipótese 4 , logo, merece atenção detalhada. Isso porque as redes de franquias brasileiras apresentaram uma maior capacidade de crescimento relativo, ao invés do esperado, que seria o maior crescimento das redes de franquias estrangeiras. Mesmo que as redes de franquias estrangeiras possam ter apelo no desejo de consumo de muitos brasileiros e possuam marcas de maior renome, estes benefícios gerados pela marca nem sempre se traduzem como o melhor condutor de crescimento em virtude das características relativas à mecânica de competição no mercado emergente (Abratt \& Motlana, 2002; Holt, Quelch, \& Taylor, 2004), no caso, o mercado brasileiro. Este resultado pode ser compreendido pelo fato de as redes de franquias brasileiras possuírem um maior domínio do mercado doméstico, ou seja, uma melhor inteligência de mercado, o que envolve a prospecção de melhores pontos de venda, o entendimento dos mercados fora dos grandes centros urbanos, a compreensão das demandas das diversas classes socioeconômicas, e as redes de parceiros e fornecedores locais estabelecidas há maior tempo. Tais aspectos são entraves inerentes à atuação em mercados emergentes, ressaltados como desafios na literatura de negócios internacionais (Khanna \& Palepu, 2011; London \& Hart, 2004; Meyer, 2004), e parecem ter impacto significativo no estudo do modelo de expansão das redes de franquias estrangerias em mercados emergentes (Alon et al., 2010; Dant et al., 2011; Dant \& Grünhagen, 2014).

O resultado das entrevistas semiestruturadas reflete que a estratégia de expansão em mercadores emergentes adotada pelas redes de franquias estrangeiras possui limitações, uma vez que existe uma alta complexidade cultural presente nestes mercados, o que pode impactar o processo de expansão da marca (Baena, 2012). Acresce ao fato que nem todas as marcas de franquias são de fato globais, isto é, muitas redes estrangeiras de franquias ainda não possuem a marca estabelecida em mercados emergentes, apesar de possuírem reputação em seu mercado e, talvez, em até alguns outros mercados internacionais (Meyer \& Tran, 2006). Por fim, o grau de adaptação no que concerne ao produto, à promoção e à distribuição não se configura como algo simples e de rápida resolução. Isto dificulta o processo de crescimento da rede de franquia, uma vez que esbarra no paradigma padronização e adaptação (Sorenson \& Sorensen, 2001), típico do processo de internacionalização de franquias. Por fim, os resultados da pesquisa quantitativa e qualitativa possuem termos gerenciais com um impacto significativo para a revisão do modelo de negócios das franquias estrangeiras no Brasil e apresenta oportunidades para as franquias domésticas. Se o crescimento relativo não expressa o prestígio e reputação global da marca da franquia estrangeira, as taxas superiores na fase de instalação e manutenção, agregadas à menor capacidade de monitoramento, têm o potencial de afugentar novos franqueados. De tal modo, as taxas devem ser revistas, assim como a estratégia de monitoramento. Nesse intermeio, as franquias domésticas têm a vantagem de impor seu modelo de negócio como mais atrativos para franqueados. Talvez isso explique os números da pequena participação estrangeira no ramo de franquias no Brasil, de apenas 159 redes perante 3.073 redes no Brasil, ou seja, aproximadamente 5\% (ABF, 2016b). Por sua vez, este aspecto nos ajuda a compreender, também, o limitado número de redes de franquias brasileiras com operações no exterior, se relacionado à capacidade de crescimento no mercado doméstico e o menor risco comparativamente ao crescimento no mercado internacional (Marques, Merlo, \& Nagano, 2009; Melo et al., 2015a, 2015b; Rocha et al., 2014).

\section{Conclusão}

O objetivo geral deste trabalho se concentrou em analisar as diferenças existentes no processo de constituição das redes de franquias estrangeiras que atuam no mercado brasileiro perante as redes domésticas. Os resultados mostram que as redes de franquias estrangeiras requerem maiores taxas de 
investimento e manutenção no país de destino. Ademais, as redes estrangeiras apresentam menor capacidade de monitoramento e controle no país de destino, assim como menor capacidade de expansão.

Tais resultados agregam à literatura dois importantes pontos. Primeiro, enriquecem os estudos comparativos sobre redes de franquias internacionalizadas (Camargo, Rocha, \& Silva, 2016; Elango, 2007; Huszagh et al., 1992; Kalnins, 2005; Kedia et al., 1995; Lafontaine \& Kaufmann, 1994; MarizPérez, \& García-Álvarez, 2009; M. I. C. Pedro, 2009; Shane, 1996a, 1998), ressaltando a importância de o processo de constituição das franquias ser analisado como um todo, ou seja, considerando em conjunto as três etapas distintas: instalação, manutenção e expansão. Os estudos realizados anteriormente não contemplam esta distinção entre as etapas da constituição das redes de franquias internacionalizadas, limitando-se a comparar a diferença entre grupos de franquias internacionalizadas e domésticas. Isso permite não só a maior compreensão do modelo de negócio, como também do lado gerencial, direcionando melhor as decisões de franqueadores e franqueados. Com isto, contribui para os executivos de franquias, diante de um melhor dimensionamento do progresso da rede de franquias em mercados internacionais, perante os drivers competitivos em cada fase de maturidade destas unidades.

A segunda contribuição teórica complementa os estudos sobre competitividade das redes de franquias estrangeiras em mercados emergentes (Dant, et al., 2011; Dant \& Grünhagen, 2014), mostrando a necessidade de essas franquias adequarem seu modelo às condições de negócios dos mercados emergentes (Aliouche et al., 2015; Alon et al., 2010; Baena \& Cerviño, 2014), ao invés de apenas se valerem do prestígio e reputação internacional. Essa contribuição demonstra a necessidade de conhecimento para operação pelas redes estrangeiras em mercados emergentes. Esses mercados possuem suas características institucionais particulares, seja por meio das licenças públicas de funcionamento, das normas culturais de negociação e de consumo, seja pelos requisitos bancários para financiamento de franquias. Em outras palavras, essa constatação se endereça, também, às decisões gerenciais das redes de franquias estrangeiras, a fim de adequar os valores de investimento e manutenção de suas franquias, e adaptar a escolha por regiões geográficas que possam se integrar ao perfil destas franquias. A simples chegada a um país emergente, valendo-se de expertise internacional e know-how de operação e marcas, não necessariamente irá posicionar essas redes em lugares de destaque nestes mercados emergentes de destino, tampouco garantir seu crescimento.

As limitações de pesquisa residiram nos critérios de seleção da amostra das redes de franquias brasileiras que atuam no Brasil. Devido ao número de redes de franquias estrangeiras que atuam no Brasil ser consideravelmente inferior ao de redes de franquias brasileiras, foi necessário realizar um recorte das redes de franquias brasileiras. Esse recorte foi qualitativo, ou seja, para selecionar as redes de franquias brasileiras que fariam parte da amostra desta pesquisa, foram levados em consideração a qualidade da rede, o desempenho da rede, a classificação em rankings de franquias e as chancelas conferidas por selos de excelência, evitando, assim, uma homogeneização da amostra por intermédio somente da idade ou do número de unidades. Outros critérios poderiam ser adotados, como o porte da franquia, entretanto poderia incorrer em um viés amostral compreendendo um determinado grupo atrelado ao tamanho da rede.

A segunda limitação de pesquisa se refere às variáveis utilizadas nesta análise como envolventes do processo de desenvolvimento de uma rede de franquias, tendo sido desconsiderados aspectos determinantes como o perfil e background do franqueado, o nível de qualidade do suporte fornecido pelo franqueador e a força da marca da rede.

A terceira limitação desta pesquisa reside na mensuração da variável capacidade de monitoramento e controle, referente à hipótese 3 , pois não foi calculada a dispersão em quilômetros entre as unidades franqueadas nem analisada a sua localidade de operação no Brasil. Por esta nova metodologia poderiam ser apresentados diferentes resultados diante da hipótese 3. Caso fosse constatada uma maior concentração geográfica das redes estrangeiras, poderia ser deduzida a existência de uma maior capacidade de monitoramento e controle. Em adição, apesar de os testes de endogeneidade do modelo (teste de Hausman - Apêndice B) mostrarem que os resíduos não estão associados significativamente à variável dependente do modelo, como não aventamos, a posteriori, variáveis instrumentais para o teste, e nossa base não fornecia essa opção, os resultados sofreram com a ausência 
dessa análise. Por fim, outra limitação deste trabalho se refere ao período, que corresponde aos dados secundários de um ano. Todavia, os dados disponíveis não permitiam fazer um painel.

Sugere-se que nas pesquisas futuras sejam realizadas comparações entre as redes de franquias brasileiras internacionalizadas e a sua estrutura de operação no exterior. Isto porque há um crescente aumento no número de redes de franquias brasileiras que têm passado por processo de internacionalização nos últimos anos. Entretanto, pouco se sabe se essas redes brasileiras estão de fato sendo competitivas no exterior. Com isso, sugere-se selecionar os países em que essas redes brasileiras estão operando e analisar a sua inserção competitiva nesses mercados, a exemplo da utilização do modelo de pesquisa que é aplicado neste estudo. Adicionalmente, sugere-se a realização de estudos que se utilizem de análises institucionais visando identificar quais características institucionais presentes no Brasil podem estar correlacionadas à tomada de decisão das redes de franquias estrangeiras para atuar no mercado brasileiro, ou mesmo em outros mercados emergentes.

\section{Referências}

Abratt, R., \& Motlana, P. (2002). Managing co-brading strategies: Global brands into local markets. Business Horizons, 45(5), 43-50. http://dx.doi.org/10.1016/S0007-6813(02)00242-2

Aliouche, E. H., Fernandez, D. B., Chanut, O., \& Gharbi, N. (2015). Institutional environments and the internationalization of franchise chains: The contrasting cases of three North African countries. Journal of Applied Business Research, 31(2), 417-436. http://dx.doi.org/10.19030/jabr.v31i2.9126

Alon, I. (2001). The use of franchising by U.S. based retailers. Journal of Small Business Management, 39(2), 111-122. http://dx.doi.org/10.1111/1540-627X.00011

Alon, I., \& Banai, M. (2000). Franchising opportunities and threats in Russia. Journal of International Marketing, 8(3), 104-119. http://dx.doi.org/10.1509/jimk.8.3.104.19634

Alon, I., \& McKee, D. (1999). The internationalization of professional business service franchises. Journal of Consumer Marketing, 16(1), 74- 85. http://dx.doi/abs/10.1108/07363769910250787

Alon, I., Toncar, M., \& Le, L. (2002). American franchising competitiveness in China. Journal of Global Competitiveness, 10(1), 65-83.

Alon, I., \& Welsh, D. H. B. (2002). Global franchising in emerging and transitioning economies. International Journal of Business and Economics, 2(1), 332-343.

Alon, I., Welsh, D., \& Falbe, C. (2010). Franchising in emerging markets. In I. Alon (Org.), Franchising globally: Innovation, learning and imitation (Vol. 1, Chap. 1, pp. 11-35). New York: PalgraveMacMillan.

Associação Brasileira de Franchising. (2014, março 11). Setor de franquias cresceu 11,9\% e faturou $R \$ 115$ Bilhões em 2013, segundo ABF. Recuperado em 10 de julho, 2015, de https://www.abf.com.br/setor-de-franquias-cresceu-119-e-faturou-r-115-bilhoes-em-2013segundo-abf/

Associação Brasileira de Franchising. (2016b, novembro 12). Internacionalização de franquias brasileiras dobrou nos últimos seis anos. Recuperado em 25 de janeiro, 2016, de https://www.abf.com.br/internacionalizacao-de-franquias-brasileiras-dobrou-nos-ultimos-seisanos/ 
Associação Brasileira de Franchising. (2016a). Relatório de desempenho do franchising em 2016. Recuperado em 15 de novembro, 2016, de https://www.abf.com.br/wpcontent/uploads/2017/06/Desempenho-do-Franchising-2016-Internacionalizacao-2.pdf

Baena, V. (2009). Modeling global franchising in emerging markets: An entry mode analysis. Journal of East-West Business, 15(3/4), 164-188. http://dx.doi.org/10.1080/10669860903435921

Baena, V. (2012). Market conditions driving international franchising in emerging markets. $\begin{array}{lllll}\text { International Journal of } & \text { Emerging }\end{array}$ http://dx.doi.org/10.1108/17468801211197879

Baena, V. (2015). European franchise expansion into Latin America: Evidence from the Spanish franchise system. Management Research Review, 38(2), 149-165. http://dx.doi.org/10.1108/MRR-08-2013-0185

Baena, V., \& Cerviño, J. (2014). International franchising decision-making: A model for country choice. Latin American Business Review, 15(1), 13-43. http://dx.doi.org/10.1080/10978526.2014.871214

Brookes, M., \& Altinay, L. (2011). Franchise partner selection: Perspectives of franchisors and franchisees. Journal of Services Marketing, 25(5), 336-348. http://dx.doi.org/10.1108/08876041111149694

Brookes, M., Altinay, L., \& Aktas, G. (2015). Opportunistic behaviour in hospitality franchise agreements. International Journal of Hospitality Management, 46, 120-129. http://dx.doi.org/10.1111/etap.12050

Camargo, M., Rocha, T., \& Silva, S. (2016). Estratégias de marketing no processo de internacionalização de franquias brasileiras. Revista Brasileira de Gestão de Negócios, 18(62), 570-592. http://dx.doi.org/10.7819/rbgn.v18i62.2804

Carvalho, M. (2000). Internacionalização de franquias: Um estudo exploratório no ramo de alimentação (Dissertação de mestrado). Universidade Federal do Rio de Janeiro, Rio de Janeiro, RJ, Brasil.

Castrogiovanni, G. J., Combs, J. G., \& Justis, R. T. (2006). Resource scarcity and agency theory predictions concerning the continued use of franchising in multi-outlet networks. Journal of Small Business Management, 44(1), 27-44. http://dx.doi.org/10.1111/j.1540-627X.2006.00152.x

Choo, S., Mazzarol, T., \& Soutar, G. (2007). The selection of international retail franchisees in East Asia. Asia Pacific Journal of Marketing and Logistics, 19(4), 380-397. http://dx.doi.org/10.1108/13555850710827878.

Combs, J. G., Ketchen, D. J., Shook, C. L., \& Short, J. C. (2011). Antecedents and consequences of franchising: Past accomplishments and future challenges. Journal of Management, 37(1), 99126.doi: $10.1177 / 0149206310386963$

Dant, R. P., \& Grünhagen, M. (2014). International franchising research: Some thoughts on the what, where, when, and how. Journal of Marketing Channels, 21(3), 124-132. http://dx.doi.org/10.1080/1046669X.2014.917012

Dant, R. P., Grünhagen, M., \& Windsperger, J. (2011). Franchising research frontiers for the twenty$\begin{array}{llll}\text { first century. Journal of } & \text { Retailing, }\end{array}$ http://dx.doi.org/10.1080/1046669X.2014.917012

Diaz-Bernardo, R. (2012). An analysis of three confronting theories to explain franchising supply. Journal of Business \& Economics Research, 10(3), 167-170. http://dx.doi.org/10.19030/jber.v10i3.6856 
Doherty, A. M., Chen, X., \& Alexander, N. (2014). The franchise relationship in China: Agency and institutional theory perspectives. European Journal of Marketing, 48(9/10), 1664-1689. http://dx.doi.org/10.1108/EJM-04-2012-0199

Doherty, A. M., \& Quinn, B. (1999). International retail franchising: An agency theory perspective. International Journal of Retail \& Distribution Management, 27(6), 224-237. http://dx.doi.org/10.1108/09590559910278588

Douglas, S. P., Craig, C. S., \& Nijssen, E. J. (2001). Integrating branding strategy across markets: Building international brand architecture. Journal of International Marketing, 9(2), 97-114. http://dx.doi.org/10.1509/jimk.9.2.97.19882

Elango, B. (2007). Are franchisors with international operations different from those who are domestic market oriented?. Journal of Small Business Management, 45(2), 179-193. http://dx.doi.org/10.1111/j.1540-627X.2007.00208.x

Eroglu, S. (1992). The internationalization process of franchise systems: A conceptual model. International Marketing Review, 9(5). http://dx.doi.org/10.1108/02651339210020277

Fladmoe-Lindquist, K., \& Jacque, L. (1995). Control modes in international service operations: The propensity to franchise. Management Science, 41(7), 1238-1249. http://dx.doi.org/10.1287/mnsc.41.7.1238

Garg, V. K., Priem, R. L., \& Rasheed, A. A. (2013). A theoretical explanation of the cost advantages of multi-unit franchising. Journal of Marketing Channels, 20(1/2), 52-72. http://dx.doi.org/10.1080/1046669X

Gigliotti, B. (2012). O funcionamento do sistema de franchising. In P. Melo \& T. Andreassi (Eds.), Franquias brasileiras (pp. 3-16). São Paulo: Cengage.

Gillis, W., Combs, J. G., \& Ketchen, D. J. (2014). Using resource-based theory to help explain plural form franchising. Entrepreneurship Theory and Practice, 38(3), 449-472. http://dx.doi.org/10.1111/etap.12008

Godoi, C. K., \& Mattos, P. L. C. L. (2006). Entrevista qualitativa: Instrumento de pesquisa e evento dialógico. In C. K. Godoi, E. Bandeira-de-Mello, \& A. B. Silva (Eds.), Pesquisa qualitativa em estudos organizacionais: Paradigmas, estratégias e métodos (pp. 301-323). São Paulo: Saraiva.

Gonzalez-Diaz, M., \& Solis-Rodriguez, V. (2012). Why do entrepreneurs use franchising as a financial tool? An agency explanation. Journal of Business Venturing, 27(3), 325-341. http://dx.doi.org/10.1016/j.jbusvent.2011.03.001

Greiner, L. E. (1972). Evolution and revolution as organizations grow. Harvard Business Review, 50, $37-46$.

Hair, J., Celsi, M., Money, A., Samouel, P., \& Page, M. (2015). Business research methods. Armonk, NY: ME Sharpe.

Hitt, A. M., Dacin, T. M., Levitas, E., Arregle, J., \& Borza, A. (2000). Partner selection in emerging and developed market contexts: Resource based and organizational learning perspectives. Academy of Management Journal, 43(1), 449-476. http://dx.doi.org/10.2307/1556404

Grünhagen, M., \& Terry, A. (2017). Development Prospects for Franchising in Southeast Asia: A Review and Outlook. In R. Benlamri \& M. Sparer (Eds.), Leadership, innovation and entrepreneurship as driving forces of the global economy (pp. 671-673). Switzerland: Springer International Publishing. 
Hoffman, R. C., Munemo, J., \& Watson, S. (2016). International franchise expansion: The role of institutions and transaction costs. Journal of International Management, 22(2), 101-114. http://dx.doi.org/10.1016/j.intman.2016.01.003

Holt, D., Quelch, J., \& Taylor, E. (2004). How global brands compete. Harvard Business Review, Boston, 82(9), 68-75.

Hoskisson, R. E., Eden, L., Lau, C. M., \& Wright, M. (2000). Strategy in emerging economies. Academy of Management Journal, 43(3), 249-267. http://dx.doi.org/10.2307/1556394

Huszagh, S. M., Huszagh, F. W., \& McIntyre, F. S. (1992). International franchising in the context of competitive strategy and the theory of the firm. International Marketing Review, 9(5). http://dx.doi.org/10.1108/02651339210020268

Jayachandran, S., Kaufman, P., Kumar, V., \& Hewett, K. (2013). Brand licensing: What drives royalty rates?. Journal of Marketing, 77(5), 108-122. http://dx.doi.org/10.1509/jm.11.0145

Jensen, M. C., \& Meckling, W. H. (1976). Theory of the firm: Managerial behavior, agency costs and ownership structure. Journal of Financial Economics, 3(4), 305-360. http://dx.doi.org/10.2139/ssrn.94043

Jeon, H., Meiseberg, B., Dant, R., \& Grünhagen, M. (2016). Cultural convergence in emerging markets: The case of McDonald's in China and India. Journal of Small Business Management, 54(2), 732749. http://dx.doi.org/10.1111/jsbm.12168

Juste, M. V. B., Palacios, L. L., \& Redondo, Y. P. (2005). Proceso de entrada y salida del mercado: Análisis del mercado de la franquicia. Cuadernos de Estudios Empresariales, (15), 9-26.

Kacker, M., Dant, R. P., Emerson, J., \& Coughlan, A. T. (2016). How firm strategies impact size of partner-based retail networks: Evidence from franchising. Journal of Small Business Management, 54(2), 506-531. http://dx.doi.org/10.1111/jsbm.12155

Kalnins, A. (2005). Overestimation and venture survival: An empirical analysis of development commitments in international master franchising ventures. Journal of Economics \& Management Strategy, 14(4), 933-953. http://dx.doi.org/10.1111/j.1530-9134.2005.00088.x

Kedia, B. L., Ackerman, D. J., \& Justis, R. T. (1995). Changing barriers to the internationalization of franchising operations: Perceptions of domestic and international franchisors. The International Executive, 37(4), 329-348. http://dx.doi.org/10.1002/tie.5060370404

Khan, Z. (2016). Determinants of a success ful cross-border knowledge transfer in franchise networks. Journal of Asia Business Studies, 10(2). http://dx.doi.org/10.1108/JABS-05-2015-0052

Khanna, T., \& Palepu, K. G. (2011). Vencendo em mercados emergentes. Havard Business Review, $88(6), 80-85$.

Klann, R. C., Klann, P. A., Postai, K. R., \& Ribeiro, M. J. (2012). Relação entre o ciclo de vida organizacional e o planejamento em empresas metalúrgicas do Município de Brusque-SC. Revista de Contabilidade e Organizações, 6(16), 119-142. http://dx.doi.org/10.11606/rco.v6i16.52670

Lafontaine, F. (1992). Agency theory and franchising: Some empirical results. The Rand Journal of Economics, 23(2), 263-283. http://dx.doi.org/10.2307/2555988

Lafontaine, F., \& Kaufmann, P. J. (1994). The evolution of ownersip patterns in franchise systems. Journal of Retailing, 70(2), 97-113. http://dx.doi.org/10.1016/0022-4359(94)90010-8 
London, T., \& Hart, S. (2004). Reinventing strategies for emerging markets: Beyond the transnational model. Journal of International Business Studies, 35(5), 350-370. http://dx.doi.org/10.1057/palgrave.jibs.8400099

Lourenço, C. E., \& Brandão, M. M. (2013). O impacto da percepção e da imagem do país de origem para o consumidor na avaliação de produtos em mercado emergentes. Revista de Administração da UNIMEP, 11(3), 173-195. http://dx.doi.org/10.15600/1679-5350/rau.v11n3p173-195

Madanoglu, M., \& Karadag, E. (2016). Corporate governance provisions and firm financial performance: The moderating effect of deviation from optimal franchising. International Journal of Contemporary Hospitality Management, 28(8), 1805-1822. http://dx.doi.org/10.1108/IJCHM09-2014-0470

Mariz-Pérez, R., \& García-Álvarez, T. (2009). The Internationalization strategy of Spanish indigenous franchised chains: A resource-based view. Journal of Small Business Management, 47(4), 514530. http://dx.doi.org/10.1108/sd.2010.05626dad.003

Marques, D. S. P., Merlo, E. M., \& Nagano, M. S. (2009). Uma análise sobre internacionalização de franquias brasileiras. Revista Eletrônica de Administração, 15(1), 78-107. Recuperado de http://seer.ufrgs.br/index.php/read/article/download/39181/25043

Melo, P. L. de R., Borini, F. M., Oliveira, M. de M., Jr., \& Parente, R. C. (2015b). International analysis of the countries where Brazilian franchise chains operate. Revista de Administração, 50(1), 2639. http://dx.doi.org/10.5700/rausp1182

Melo, P. L. de R., Borini, F. M., Oliveira, M. de M., Jr., \& Parente, R. C. (2015a). Internationalization of Brazilian franchise chains: A comparative study. Revista de Administração de Empresas, 55(3), 258-272. http://dx.doi.org/10.1590/S0034-759020150303

Merrieles, M. (2014). International franchising researche and pratice: Past, present and future. Journal of Marketing Channels, 23(3), 133-142. http://dx.doi.org/10.1080/1046669X.2014.917013

Meyer, K. E. (2004). Perspectives on multinational enterprises in emerging economies. Journal of International Business Studies, 35(4), 259-276. http://dx.doi.org/10.1057/palgrave.jibs.8400084

Meyer, K. E., Estrin, S., Bhaumik, S. K., \& Peng, M. W. (2009). Institutions, resources, and entry strategies in emerging economies. Strategic Management Journal, 30(1), 61-80. http://dx.doi.org/10.1002/smj.720

Meyer, K. E., \& Tran, Y. T. T. (2006). Market penetration and acquisition strategies for emerging economies. Long Range Planning, 39(2), 177-197. http://dx.doi.org/10.1016/j.lrp.2006.04.004

Miller, D., \& Friesen, P. H. (1984). A longitudinal study of the corporate life cycle. Management Science, 30(10), 1161-1183. http://dx.doi.org/10.1016/j.lrp.2006.04.004

Morse, J. M. (1991). Approaches to qualitative-quantitative methodological triangulation. Nursing Research, 40(2), 120-123. http://dx.doi.org/10.1097/00006199-199103000-00014

Ni, L., \& Alon, I. (2010). US-based fast-food restaurants: Factors influencing the international expansion of franchise systems. Journal of Marketing Channels, 17(4), 339-359. http://dx.doi.org/10.1080/1046669X.2010.512861

Oxenfeldt, A. R., \& Kelly, A. O. (1969). Will successful franchise systems ultimately become whollyowned chains? Journal of Retailing, 44(4), 69-83.

Paswan, A., \& Rajamma, R. K. (2016). Franchising, knowledge transfer, and development in emerging markets. In K. Plangger (Ed.), Thriving in a new world economy. Developments in marketing 
science: Proceedings of the academy of marketing science (pp. 173-180). Atlanta: Springer. https://doi.org/10.1007/978-3-319-24148-7_9

Pedro, I., Filipe, J. A., \& Reis, E. (2008). Factores determinantes da internacionalização das redes de franchising ibéricas. Economia Global e Gestão, 13(1), 65-84.

Pedro, M. I. C (2009). Agency theory and the franchising internationalization intention. International Journal of Academic Research, 1(2), 165-172.

Plá, D. (2001). Tudo sobre franchising. Rio de Janeiro: SENAC.

Polo-Redondo, Y., Bordonaba-Juste, V., \& Palacios, L. L. (2011). Determinants of firm size in the franchise distribution system: Empirical evidence from the Spanish market. European Journal of Marketing, 45(1/2), 170-190. http://dx.doi.org/10.1108/03090561111095649

Preble, J. F. (1993). Global expansion: The case of US fast-food franchisors. Journal of Global Marketing, 6(1/2), 185-206. http://dx.doi.org/10.1300/J042v06n01_10

Quinn, B. (1998). Towards a framework for the study of franchising as an operating mode for international retail companies. The International Review of Retail, Distribution and Consumer Research, 8(4), 445-467. http://dx.doi.org/10.1080/095939698342751

Rocha, T., Borini, F., Spears, E., Ogasavara, M., Khauaja, D., Camargo, A., \& Melo, P. (2014). Estágios da internacionalização das franquias brasileiras. São Paulo: ESPM.

Schreiber, D., \& Szyszko, F. S. (2014). Estudo da alternativa de franchising com base no caso da franquia Doutor Resolve. Revista da Micro e Pequena Empresa, 8(1), 18-31. http://dx.doi.org/10.6034/641

Shane, S. A. (1996a). Hybrid organizational arrangements and their implications for firm growth and survival: A study of new franchisors. Academy of Management Journal, 39(1), 216-234. http://dx.doi.org/10.2307/256637

Shane, S. A. (1996b). Why franchise companies expand overseas. Journal of Business Venturing, 11(2), 73-88. http://dx.doi.org/10.1016/0883-9026(95)00110-7

Shane, S. A. (1998). Explaining the distribution of franchised and company-owned outlets in franchise $\begin{array}{llll}\text { systems. Journal } & \text { 717-739. }\end{array}$ http://dx.doi.org/10.1177/014920639802400603

Shane, S. A., Shankar, V., \& Aravindakshan, A. (2006). The effects of new franchisor partnering strategies on franchise system size. Management Science, 52(5), 773-787. http://dx.doi.org/10.1287/mnsc.1050.0449

Sorenson, O., \& Sorensen, J. B. (2001). Finding the right mix: Franchising, organizational learning, and chain performance. Strategic Management Journal, 22(6/7), 713-724. http://dx.doi.org/10.1002/smj.185

Sun, K. A., \& Lee, S. (2016). Risk-sharing as a long-term motivation to franchise: Role of franchising experience. The Journal of Hospitality Financial Management, 24(1), 20-32. http://dx.doi.org/10.1080/10913211.2016.1166025

Welsh, D. H. B., \& Alon, I. (2002). International franchising in industrialized markets: North America, the Pacific Rim, and others countries. Chicago, IL: CCH.

Welsh, D. H. B., Alon, I., \& Falbe, C. M. (2006). An examination of international retail franchising in emerging markets. Journal of Small Business Management, 44(1), 130-149. http://dx.doi.org/10.1111/j.1540-627X.2006.00158.x 
Wu, C.-W. (2015). Antecedents of franchise strategy and performance. Journal of Business Research. 68(7), 1581-1588. http://dx.doi.org/10.1016/j.jbusres.2015.01.055

\section{Dados dos Autores}

\section{Victor Ragazzi Isaac}

Rua Dr. Bacelar, 1212, 04026-002, São Paulo, SP, Brasil. E-mail: victor.ragazzi@gmail.com; h4nd@ hotmail.com

Pedro Lucas Resende Melo

Rua Dr. Bacelar, 1212, 04026-002, São Paulo, SP, Brasil. E-mail: resendemelo@usp.br

Felipe Mendes Borini

Rua Dr. Álvaro Alvim, 123, 04018-010, São Paulo, SP, Brasil. E-mail: fborini@espm.br 


\section{APÊNDICE A}

A respeito das possíveis diferenças entre as redes, que podem ser decorrentes do setor, e não da origem da rede, consideramos apropriado mostrar os resultados de alguns testes estatísticos. Como pode ser verificado na Tabela 1 de testes de médias, não existe diferença significativa da taxa de investimento entre os setores da amostra estudada.

Tabela 1

\section{Teste de Diferenças de Médias da Taxa de Investimento para o Setor}

\begin{tabular}{llcccc}
\hline Setor & N & Média & Desvio Padrão & F & Sig. \\
\hline alimentação & 49 & 217,94 & 185,32 & 0,775 & 0,543 \\
\hline educação & 36 & 169,51 & 140,21 & & \\
\hline moda & 33 & 240,39 & 147,78 & & \\
\hline saúde & 25 & 178,96 & 160,44 & & \\
\hline outros & 45 & 38,64 & $1.270,03$ & & \\
\hline
\end{tabular}

Nota. Fonte: Elaborada pelos autores.

Ademais, quando se realiza a regressão moderando a variável taxa de investimento pelo setor (Tabela 2), os resultados também mostram que a moderação do setor não apresenta significância. Isso deixa claro que, embora possam existir suposições de que a taxa de investimento esteja associada ao setor, esse não é o caso para a amostra do presente artigo.

Tabela 2

\section{Modelo de Regressão}

\begin{tabular}{ll}
\cline { 2 - 2 } & Modelo \\
\hline Constante & $-1,946^{* *}$ \\
\hline $\mathrm{H} 1 \mathrm{~b}$ & $1,215^{* *}$ \\
\hline $\mathrm{H} 2 \mathrm{~b}$ & $0,688^{* *}$ \\
\hline $\mathrm{H} 3 \mathrm{~b}$ & $-0,510^{* *}$ \\
\hline $\mathrm{H} 4 \mathrm{~b}$ & $-0,748^{* *}$ \\
\hline Alimentação*H1 & $-0,795$ \\
\hline Educação*H1 & $-0,779$ \\
\hline Moda*H1 & $-3,948$ \\
\hline Saúde*H1 & 4,587 \\
\hline Alimentação & 0,496 \\
\hline Educação & $-0,239$ \\
\hline Saúde & 0,762 \\
\hline Moda & 0,762 \\
\hline
\end{tabular}

Nota. Fonte: Elaborada pelos autores. 


\section{APÊNDICE B}

Em relação à possível endogeneidade, apresentamos a Tabela 3, com o modelo de regressão com os erros das variáveis das quatro hipóteses, resultante da aplicação do teste de Hausman. O resultado mostra a ausência de associação dos resíduos com a variável dependente (ver valor t entre parênteses). Isso afasta a suspeita da endogeneidade e simultaneidade.

Tabela 3

\section{Teste para a Endogeneidade}

\begin{tabular}{ll}
\hline & B (valor teste t para resíduos) \\
\hline Constante & 0,365 \\
\hline ResH1 & $-0,771(-0,296)$ \\
\hline ResH2 & $-1,375(-0,553)$ \\
\hline ResH3 & $0,776(0,692)$ \\
\hline ResH4 & $0,667(0,981)$ \\
\hline H1b & 1,118 \\
\hline H2b & 1,589 \\
\hline H3b & $-0,951$ \\
\hline H4b & $-0,581$ \\
\hline
\end{tabular}

Nota. Fonte: Elaborada pelos autores. 